\title{
La RFG en chiffres ${ }^{1}$
}

\section{Nombre de consultations d'articles}

\begin{tabular}{|l|l|l|l|}
\hline Lieu de consultation & $\mathbf{2 0 1 7}$ & $\mathbf{2 0 1 8}$ & $\mathbf{2 0 1 9}$ \\
\hline En institutions & 160045 & 174327 & 199918 \\
\hline Hors institutions & 847057 & 1033720 & 1289791 \\
\hline Total & 1007102 & 1208047 & 1489709 \\
\hline
\end{tabular}

Source : statistiques.cairn.info

\section{Top 5 des institutions}

En 2017

\begin{tabular}{|l|l|l|l|}
\hline \multicolumn{2}{|l|}{ Institutions francophones } & Institutions non francophones \\
\hline Aix-Marseille Université & 4898 & New York University & 220 \\
\hline Université Lyon 3 & 3846 & ESFAM & 138 \\
\hline Université Rennes 1 & 3761 & University of Bath & 122 \\
\hline Université Paris Dauphine & 3719 & University of Windsor & 118 \\
\hline Université Paris 1-Sorbonne & 3434 & West University of Timisoara & 87 \\
\hline
\end{tabular}

Source : statistiques.cairn.info

DOI: $10.3166 /$ rfg.2020.00423 @ 2020 Lavoisier

1. Ces données ont été transmises à la section 37 économie-gestion du CNRS dans le cadre de l'établissement de la liste 2020 de catégorisation des revues scientifiques en économie-gestion 
12 Revue française de gestion - $\mathrm{N}^{\circ} 286 / 2020$

En 2018

\begin{tabular}{|l|l|l|l|}
\hline \multicolumn{2}{|l|}{ Institutions francophones } & \multicolumn{2}{l|}{ Institutions non francophones } \\
\hline Aix-Marseille Université & 5172 & West University of Timisoara & 619 \\
\hline Université Rennes 1 & 4959 & University of Bath & 168 \\
\hline Université Paris Dauphine & 3834 & CURDES & 115 \\
\hline Université Paris 1-Sorbonne & 3577 & ESFAM & 100 \\
\hline KEDGE Bordeaux & 3558 & Katholieke Universiteit Leuven & 89 \\
\hline
\end{tabular}

Source : statistiques.cairn.info

En 2019

\begin{tabular}{|l|l|l|l|}
\hline \multicolumn{2}{|l|}{ Institutions francophones } & \multicolumn{2}{l|}{ Institutions non francophones } \\
\hline Université de Rennes & 6326 & West University of Timisoara & 285 \\
\hline Aix-Marseille Université & 5408 & University of Winnipeg & 113 \\
\hline Université Paris 1-Sorbonne & 4780 & McGill University & 102 \\
\hline CNAM & 4526 & Concordia University & 99 \\
\hline Université de Lille & 4361 & ESFAM & 99 \\
\hline
\end{tabular}

Source : statistiques.cairn.info

\section{Top 10 des pays}

En 2017

\begin{tabular}{|l|l|l|l|}
\hline \multicolumn{2}{|l|}{ En institutions } & Hors institutions \\
\hline France & 121980 & France & 433763 \\
\hline Canada & 13367 & Maroc & 83607 \\
\hline Belgique & 7657 & Tunisie & 36719 \\
\hline Maroc & 4139 & États-Unis avertissement & 36118 \\
\hline Suisse & 3272 & Algérie & 31875 \\
\hline
\end{tabular}


- (suite)

\begin{tabular}{|l|l|l|l|}
\hline En institutions & Hors institutions \\
\hline Tunisie & 2841 & Canada & 25838 \\
\hline Algérie & 1991 & Belgique & 22997 \\
\hline Liban & 588 & Cameroun & 22451 \\
\hline Sénégal & 574 & Côte d'Ivoire & 16211 \\
\hline Cameroun & 525 & Royaume-Uni & 14264 \\
\hline
\end{tabular}

Source : statistiques.cairn.info

En 2018

\begin{tabular}{|l|l|l|l|}
\hline En institutions & Hors institutions \\
\hline France & 131559 & France & 480922 \\
\hline Canada & 15216 & Maroc & 102397 \\
\hline Belgique & 7729 & États-Unis avertissement & 92706 \\
\hline Maroc & 4536 & Algérie & 39485 \\
\hline Suisse & 4019 & Tunisie & 34935 \\
\hline Tunisie & 2292 & Canada & 31738 \\
\hline Algérie & 1535 & Cameroun & 27688 \\
\hline Sénégal & 1503 & Belgique & 26229 \\
\hline Roumanie & 700 & Côte d'Ivoire & 21272 \\
\hline Liban & 638 & Sénégal & 15869 \\
\hline
\end{tabular}

Source : statistiques.cairn.info 
14 Revue française de gestion $-\mathrm{N}^{\circ} 286 / 2020$

En 2019

\begin{tabular}{|l|l|l|l|}
\hline En institutions & Hors institutions \\
\hline France & 144935 & France & 362212 \\
\hline Canada & 12590 & États-Unis avertissement & 142482 \\
\hline Belgique & 8577 & Maroc & 74594 \\
\hline Maroc & 4484 & Algérie & 26241 \\
\hline Suisse & 3791 & Cameroun & 24337 \\
\hline Tunisie & 2208 & Tunisie & 23759 \\
\hline Sénégal & 1850 & Canada & 21977 \\
\hline Togo & 1328 & Belgique & 21973 \\
\hline Algérie & 953 & Côte d'Ivoire & 15503 \\
\hline Liban & 503 & Sénégal & 13727 \\
\hline
\end{tabular}

Source : statistiques.cairn.info

\section{Facteurs d'impact pour la Revue française de gestion}

\begin{tabular}{|l|l|l|l|l|}
\hline Données & \multicolumn{4}{|l|}{} \\
\hline Période considérée & $1983-2019$ & -10 ans & -5 ans & -3 ans \\
\hline Nombre d'articles pris en compte & 1000 (max) & 1000 (max) & 497 & 310 \\
\hline Citations /année & 840,65 & 979,55 & 736,7 & 177,8 \\
\hline Citations / papier & 31,1 & 10,78 & 8,89 & 2,29 \\
\hline h-index & 73 & 39 & 20 & 12 \\
\hline g-index & 116 & 74 & 59 & 16 \\
\hline $\begin{array}{l}\text { Nb de citations de l'article le plus } \\
\text { cité sur la période }\end{array}$ & & & & 51 \\
\hline Rang CNRS actuel & 3 & & & \\
\hline
\end{tabular}

Source : PoP. Dates de mesure : 29 et 30 janvier 2020, 3 février 2020 (Finance). 